\title{
OPERAÇÕES LAPAROSCÓPICAS CONSERVADORAS DO BAÇO PARA TRATAR DOR ESPLÊNICA POR ISQUEMIA
}

\author{
Conservative laparoscopic operations of the spleen for treatment of splenic pain \\ due to ischemia
}

\author{
Andy PETROIANU, Marco Antonio CABEZAS-ANDRADE, René BERINDOAGUE-NETO
}

ABCDDV/519

Petroianu A, Cabezas-Andrade MA, Berindoague-Neto R. Operações laparoscópicas conservadoras do baço para tratar dor esplênica por isquemia. ABCD Arq Bras Cir Dig 2007; 20(1):17-22.

RESUMO - Racional - Desde 1979 este grupo de autores executa esplenectomia conservadora através de esplenectomia sub-total e autotransplante esplênico. Estes procedimentos foram realizados em mais de 300 pacientes para tratar diferentes condições patológicas. Objetivo-Apresentar proposta original e inédita em seres humanos de esplenectomia subtotal, preservando apenas o pólo superior do baço por via laparoscópica e esplenectomia total complementada por implante autógeno de tecido esplênico, também pela via laparoscópica, como nova forma de tratamento da dor severa devida à isquemia do baço. Métodos - Três pacientes com intensa dor no hipocôndrio esquerdo foram submetidos a grande número de exames para concluir que sua dor era provocada por isquemia de parte do baço. A dor era resistente a todos os métodos conservadores utilizados. Decidiu-se, então, pelo tratamento cirúrgico por meio da esplenectomia subtotal, preservando o pólo superior do baço suprido pelos vasos esplenogástricos em dois casos, e esplenectomia total complementada por implante no omento maior de 20 fragmentos retirados desse baço, no terceiro caso. As três operações foram realizadas por via laparoscópica. Os três doentes foram acompanhados com exames hematológicos, imunológicos, tomográficos e cintilográficos. Resultados - Esses procedimentos foram conduzidos sem risco para os paciente e com sangramento mínimo. Não houve dificuldade técnica nem complicações per ou pós-operatórias. No seguimento, não foram constatadas anormalidades, comprovando-se a vitalidade e a função dos remanescentes esplênicos. A dor esplênica desapareceu desde o dia da operação e não retornou durante o período de acompanhamento. Conclusão - A esplenectomia subtotal e os auto-implantes esplênicos são factíveis por via laparoscópica, de maneira segura para os doentes e devem deve ser considerados no tratamento da dor de origem isquêmica do baço.

DESCRITORES - Baço. Esplenectomia parcial. Esplenectomia subtotal. Esplenectomia laparoscópica. Auto-implantes esplênicos. Isquemia esplênica. Dor esplênica.

\section{INTRODUÇÃO}

O risco de sepse pós-esplenectomia tem estimulado os procedimentos conservadores do baço, sempre que possível $^{5}$. A manutenção de parênquima esplênico preserva as funções do baço e a defesa sistêmica contra infecção ${ }^{5}$. As pesquisas sobre operações conservadoras do baço, por meio de esplenectomia subtotal, na qual se preserva o seu pólo superior suprido apenas pelos vasos esplenogástricos e de esplenectomia total complementada por implantes esplênicos autógenos suturados sobre o omento maior foram iniciadas em 1979.

Após extensos estudos experimentais, em 1984, este grupo realizou a primeira esplenectomia subtotal em uma paciente com hipertensão porta esquistossomática. Essa operação foi complementada com derivação esplenorrenal centralizada. O sucesso terapêutico obtido com esse procedimento, tanto complementado com derivação venosa quanto com desconexão portavarizes, fez com que fosse

Trabalho realizado no Instituto Alfa de Gastroenterologia do Hospital das Clínicas da UFMG, Belo Horizonte, MG, Brasil Endereço para correspondência: Andy Petroianu, e-mail: petroian@medicina.ufmg.br estendida a esplenectomia subtotal para outras indicações. Dessa maneira, a preservação apenas do pólo superior esplênico foi realizada para tratar trauma esplênico grave, hepatoesplenomegalia mielóide, doença de Gaucher, leucemia linfocítica crônica, doença de Hodgkin, hemangioma esplênico, hipodesenvolvimento somático e sexual decorrente de esplenomegalia, e doenças benignas corpocaudais do pâncreas. Em todos os casos, os resultados foram muito bons, o que resultou em gratificante experiência, superior a 200 pacientes operados com bom êxito $9,10,11,13,14,15,17,19,20,25$.

Nos casos em que não é possível preservar pelo menos parte do baço em posição ortotópica, existe a alternativa do transplante autógeno de tecido esplênico. Apesar de esse procedimento já ser conhecido desde o século XIX, há ainda poucos relatos de sua aplicação terapêutica ${ }^{4,5,8,28}$.

Os estudos sobre o auto-implante esplênico iniciaram nesta linha de pesquisa em 1985. Após cinco anos de experimentos em camundongos, ratos e coelhos e cães, aliado a suporte da literatura, obteve-se autorização institucional para realizar essa operação em pacientes esplenectomizados por diversas afecções ${ }^{18,22}$. Assim, nos últimos 16 anos estes autores realizaram esplenectomia total complemen- 
tada com implante de tecido esplênico autógeno no omento maior em mais de 100 doentes, por trauma esplênico grave, hipertensão porta esquistossomática, doença de Gaucher, hepatoesplenomegalia mielóide e leucemia linfocítica crônica ${ }^{18,22,26}$. Em todos os casos, os resultados foram gratificantes, com a comprovação da eficácia dos implantes em preservar funções do baço.

Com os avanços tecnológicos e a experiência dos cirurgiões com a cirurgia laparoscópica, foi possível realizar a esplenectomia por via laparoscópica a partir de 1991. Desde então, seguiram-se muitas publicações na literatura sobre esse tipo de procedimento, para tratar principalmente doenças hematológicas, em crianças e adultos, com resultados mais favoráveis, em baços com dimensões próximas ao normal, do que os obtidos nas operações por laparoto$\mathrm{mia}^{1,3,23}$. Como uma nova etapa na cirurgia esplênica por via laparoscópica, foi proposta a esplenectomia parcial, com o objetivo de se preservarem as funções do baço e prevenir a sepse pós-esplenectomia ${ }^{27,30}$. Entretanto, esse procedimento depende da preservação do pedículo esplênico ${ }^{1,2,3,23,24,27,29,30}$. De acordo com experiência prévia da equipe, existe a possibilidade de preservar-se o pólo superior esplênico, mesmo quando for ligado e seccionado o pedículo vascular do baço, pois, essa parte do órgão recebe também o suprimento sangüíneo por meio dos vasos esplenogástricos.

Há situações em que não é possível manter sequer parte dele, obrigando à esplenectomia total. Nesses casos, se não houver contra-indicação para conservar tecido esplênico, pode realizar-se o auto-implante esplênico.

Os objetivos do presente trabalho são apresentar proposta original e inédita em seres humanos de realizar a esplenectomia subtotal, preservando apenas o pólo superior do baço suprido pelos vasos esplenogástricos por via laparoscópica e apresentar o primeiro relato da literatura de esplenectomia total complementada por implante autógeno de tecido esplênico, por via laparoscópica.

\section{MÉTODOS}

Foram estudados dois pacientes do sexo masculino, leucodérmicos, com idades de 28 e 24 anos, que procuraram auxílio por dor intensa no hipocôndrio esquerdo. O primeiro era um atleta que teve de interromper as suas atividades profissionais em decorrência da dor. O segundo, era um estudante que não conseguia participar de atividades físicas e até sociais por causa da dor e permanecia a maior parte do tempo em repouso. Ambos os pacientes foram submetidos a exames físicos e complementares, incluindo avaliações psiquiátricas, sem que se encontrasse anomalia alguma.

Exame tomográfico realizado no primeiro paciente mostrou angulação do pólo esplênico superior sobre o restante do órgão, provavelmente em decorrência de lassidão dos ligamentos suspensores do baço e que provocavam isquemia por compressão de seu pedículo vascular. No segundo, o exame tomográfico contrastado indicava múltiplas áreas de isquemia na parte distal do baço. Ambos os órgãos tinham dimensões normais e nenhuma outra anormalidade foi encontrada.
Após ampla reunião discussão médica e com o consentimento dos pacientes, decidiu-se realizar a esplenectomia subtotal, com o objetivo de resolver a dor de origem esplênica, sem que os pacientes se tornassem asplênicos e corressem os riscos de sepse decorrentes desse quadro. A opção por preservar o pólo superior do baço fundamentou-se no achado da tomografia, que mostrou ausência dos sinais de isquemia nessa parte do órgão.

Uma terceira paciente, leucodérmica, de 33 anos foi submetida a extensa propedêutica com vista ao esclarecimento de dor muito intensa no hipocôndrio esquerdo, que a impedia de realizar até os menores esforços físicos. Em decorrência desse desconforto ela era privada de atividades profissionais, familiares e sociais, permanecendo a maior parte do tempo em repouso. Ela foi atendida dezenas de vezes em serviços de pronto-atendimento e era acompanhada por diferentes médicos, inclusive psiquiatras, sem resultados favoráveis.

Assim como ocorreu com os outros dois doentes, ao exame físico, não foi identificada alteração alguma que explicasse sua dor. O baço não era palpável e a compressão abdominal não a incomodava. Os exames hematológico, imunitário, metabólico e parasitário eram normais. No entanto, a tomografia computadorizada abdominal mostrou um baço de dimensões normais, com focos isquêmicos disseminados em todo o parênquima. Não foram encontradas outras anomalias.

Discutiram-se todos os aspectos do tratamento cirúrgico com a paciente e com a equipe médica e propôs-se a esplenectomia total complementada com o implante de tecido esplênico no omento maior, como uma forma de tratar essa dor. A paciente consentiu com o tratamento, que foi realizado por via laparoscópica.

Nos três casos, sob anestesia geral, os pacientes foram posicionados em decúbito oblíquo direito, com a colocação de um coxim sob o rebordo costal direito. $\mathrm{O}$ pneumoperitônio foi obtido por meio de uma agulha de Veress. Os quatro portais foram posicionados de acordo com o usualmente utilizado para esplenectomia total, próximo ao rebordo costal esquerdo ${ }^{1,2,3,27,30}$. Inicialmente, o tronco da artéria esplênica foi clipado na borda superior do pâncreas. Em seguida, os ramos e afluentes do pedículo vascular esplênico para o baço foram clipados e seccionados. O hilo esplênico foi dissecado para a artéria e veia esplênicas serem triplamente clipadas e seccionadas. Os ligamentos frenocólico, esplenorrenal e esplenofrênico foram seccionados com o auxílio de um gancho conectado a eletrocautério.

Nos dois pacientes em que se realizou a esplenectomia subtotal, o ligamento esplenogástrico com seus vasos foi preservado, para manter a vitalidade do pólo superior esplênico. Após a desvascularização do hilo e da parte distal do baço, observou-se a nítida demarcação entre a parte rósea, bem vascularizada do pólo esplênico superior, e o restante do baço azulado por isquemia.

No primeiro desses dois pacientes introduziu-se, por um trocarte de $18 \mathrm{~mm}$, um grampeador laparoscópico linear de $45 \mathrm{~mm}$ que foi posicionado em torno da linha que 
delimitava as duas partes do baço. Grampos de aço com dimensão de $1,5 \mathrm{~mm}$ foram disparados e, em seguida, o órgão foi seccionado com a lâmina do grampeador. Foi necessária apenas uma grampeada para a adequada hemostasia e o fechamento do parênquima esplênico. Não foi necessária sutura adicional nem outra técnica de hemostasia ou síntese esplênica ${ }^{21,29}$.

No segundo paciente, o baço foi seccionado na transição entre as partes viável e isquêmica com auxílio de um gancho conectado a eletrocautério. (Figura 1a). A hemostasia suplementar do parênquima foi obtida com o cautério untado por pomada de lidocaína (Figura 1b). A parte distal do baço foi removida dentro de uma bolsa de plástico pelo portal de $18 \mathrm{~mm}$ localizado no flanco esquerdo.
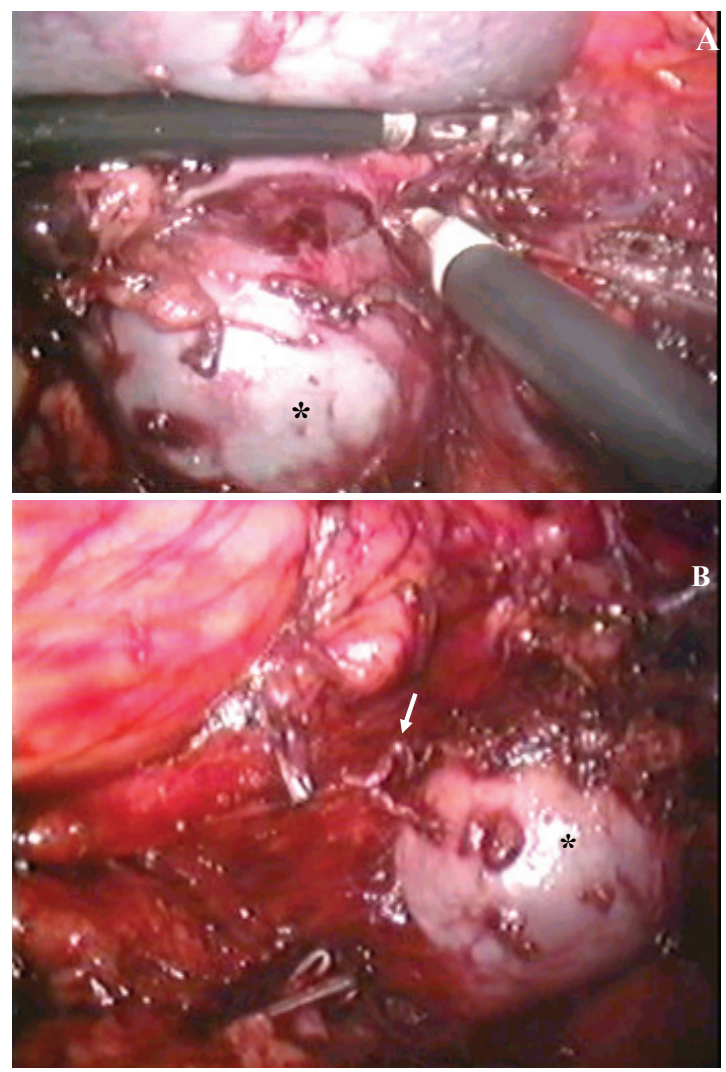

FIGURA 1 - Esplenectomia subtotal por via laparoscópica no segundo paciente com dor esplênica do baço. Observa-se em A secção esplênica, utilizando gancho conectado a eletrocautério e untado com pomada de lidocaína. O pólo superior esplênico $\left(^{*}\right)$ está separado pelo gancho do restante do baço (seta). Em B, vista cirúrgica do pólo superior esplênico $(*)$ unido ao estômago pelos ligamentos e vasos esplenogástricos (seta). Observar a camada de lidocaína formando um coágulo sobre a área cruenta da parte superior do remanescente esplênico

$\mathrm{Na}$ terceira paciente, realizou-se a esplenectomia total após a desvascularização de todo o baço. Ele foi removido dentro de uma bolsa de plástico apropriada para esse procedimento. Em seguida, fora do abdome, foram cortados 20 fragmentos de tecido esplênico, medindo cerca de dois centímetros e pesando cada um deles ao redor de quatro gramas. Todos esses segmentos foram introduzidos dentro do abdome pelo portal subcostal esquerdo e alocados no leito do baço. Com o auxílio de um fio de Vicryl ${ }^{\circledR} 3-0$, as secções de parênquima foram fixadas com sutura contínua sobre o omento maior estendido (Figura 2a). Terminada a sutura de todos os fragmentos, o omento foi dobrado sobre si e recobriu todo o tecido esplênico implantado.
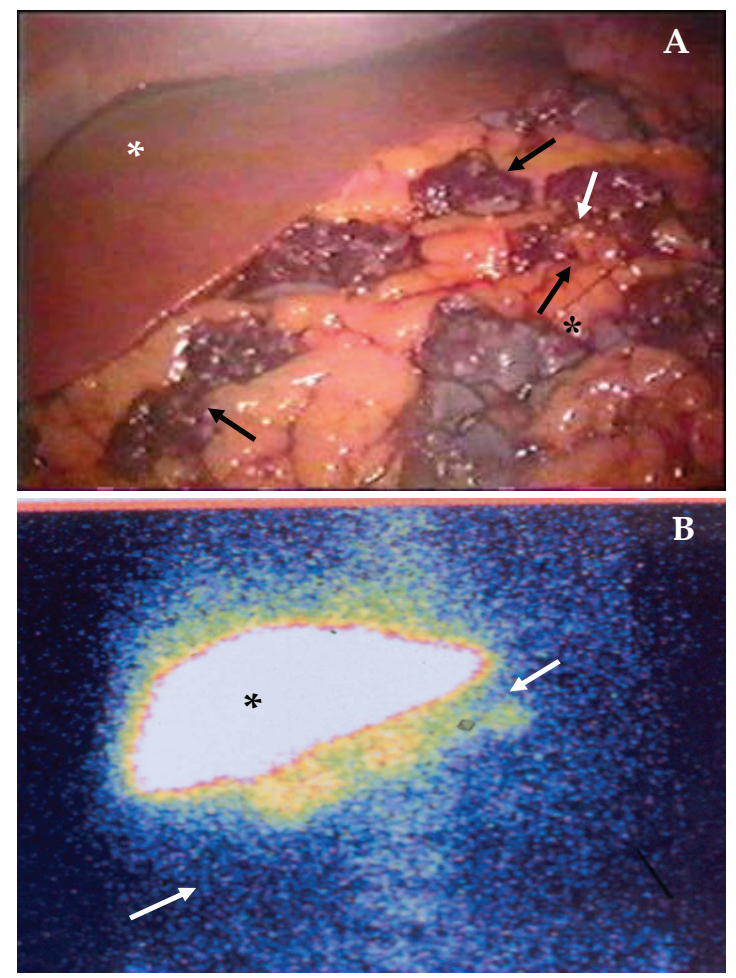

FIGURA 2 - Implante de tecido esplênico autógeno (setas) sobre o omento maior, próximo ao fígado $(*)$. Em A, vista cirúrgica do tecido esplênico suturado sobre o omento maior. Em B, imagem cintilográfica do tecido esplênico localizado no omento maior que foi enrolado sobre si, cobrindo os implantes

Os segmentos esplênicos e o baço removidos foram estudados histologicamente.

Os três pacientes foram acompanhados com exames clínicos e tomografia computadorizada, além de cintilografia com enxofre coloidal marcado com tecnécio-99m, para avaliar a morfologia e as funções do remanescente esplênico.

\section{RESULTADOS}

O tempo operatório nos três casos foi de aproximadamente 200 minutos e com sangramento mínimo. Não houve dificuldade técnica nem adversidades trans ou pósoperatórias.

Desde o primeiro dia pós-operatório, os três pacientes relataram alívio da dor esplênica, que desapareceu completa e definitivamente. A evolução clínica foi sem anormalidades e a dieta foi reintroduzida oito horas após a operação. A alta hospitalar em boas condições gerais foi autorizada no segundo dia depois do procedimento cirúr- 
gico. O primeiro doente retornou às suas atividades atléticas e os outros dois pacientes passaram a ter uma vida normal em todos os aspectos. Os acompanhamentos clínicos e psiquiátricos do pré-operatório tornaram-se desnecessários e foram interrompidos.

Os pacientes foram submetidos à nova tomografia computadorizada de abdome no primeiro dia pós-operatório, que mostrou o pólos superiores esplênicos presentes e supridos pelos vasos esplenogástricos. Os exames hematológicos e imunológicos do pós-operatório foram todos normais, sem a presença de corpúsculos eritrocitários anômalos. As tomografias e as cintilografias realizadas anualmente mostraram que os remanescentes esplênicos não alteraram suas dimensões no período registrado e mantiveram suas funções de remover o colóide de enxofre injetado na circulação sangüínea (Figuras 2b, 3a, 3b). Imagens sugestivas de isquemia não foram verificadas nesses estudos.

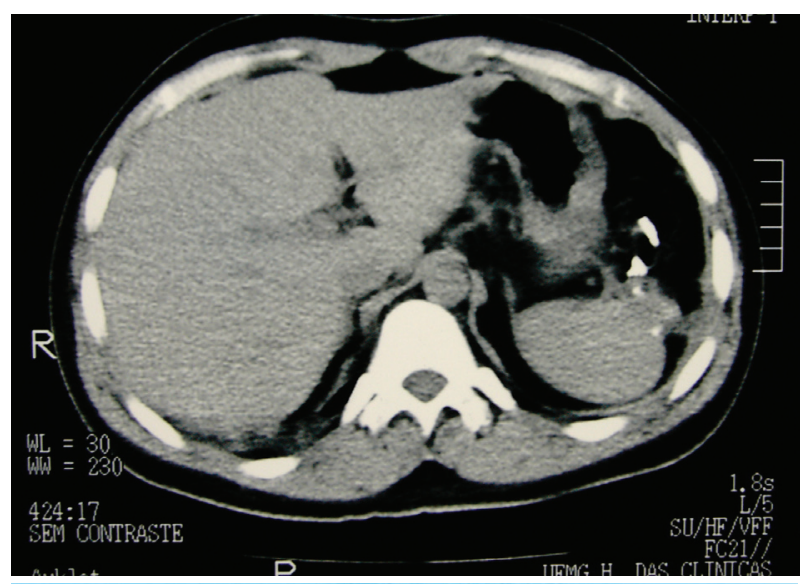

B

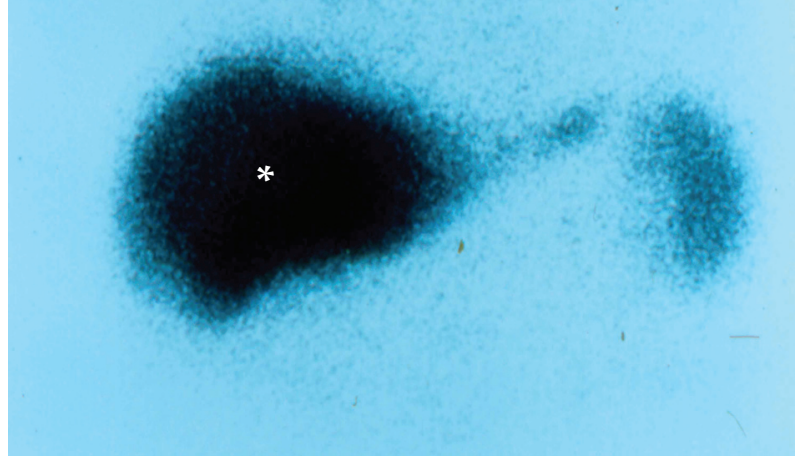

FIGURA 3 - Controle imaginológico pós-operatório no segundo paciente submetido a esplenectomia subtotal por via laparoscópica. Observa-se em A tomografia computadorizada abdominal que mostra o pólo superior esplênico remanescente $(*)$ suprido pelos vasos esplenogástricos (seta), que conectam essa parte do baço ao fundo do estômago. Em B, imagem cintilográfica do pólo superior esplênico remanescente (seta), indicando sua boa função de captação do enxofre coloidal marcado com 99m-tecnécio, injetado na circulação sangüínea. Observar também a imagem do fígado $(*)$

A análise histológica dos baços revelou focos hemorrágicos associados à trombose venosa, disseminados pelo parênquima. Nenhuma doença hematológica, granulomatosa, metabólica ou parasitária foi encontrada.

\section{DISCUSSÃO}

A dor esplênica ainda não é bem compreendida, apesar de existirem muitas teorias e estudos nesse sentido. Esse sintoma é usualmente descrito após atividade física aeróbica intensa e em presença de doenças hematológicas, como talassemia, esferocitose e leucoses. Procedimentos de embolização arterial do baço, abscessos e hematomas esplênicos também podem ser dolorosos. Por outro lado, trombos na veia e até na artéria esplênica raramente se acompanham de dor. As neoplasias de baço também não são dolorosas.

Os riscos de sepse pós-esplenectomia e de anomalias metabólicas encorajaram os médicos a preservarem o baço total ou parcialmente sempre que não houvesse contraindicação à manutenção. A esplenectomia parcial por via laparoscópica já havia sido descrita previamente ${ }^{24,27,30}$. No entanto, este é o primeiro relato de esplenectomia subtotal terapêutica por laparoscopia.

Em trabalhos experimentais e clínicos prévios verificaram-se factíveis operações esplenorredutoras por via laparoscópica ${ }^{21,24,27,30}$. O objetivo do presente relato foi mostrar que a esplenectomia subtotal e o implante de tecido esplênico autógeno também pode ser realizado sem dificuldade e com segurança por laparoscopia. Especificamente nestes casos, obteve-se cura de dor intensa e incapacitante para atividades habituais.

Ainda de maneira original, este trabalho revela uma nova técnica de secção esplênica, utilizando o gancho laparoscópico untado com lidocaína, para hemostasia do parênquima remanescente. Estes autores desenvolveram esta tática de hemostasia para sangramentos em lençol e a utilizaram com sucesso em hepatectomias para câncer, em biopsias hepáticas por laparoscopia, em área cruenta de osteotomia, no retroperitônio e em outras operações abdominais. O gel de lidocaína, quando submetido ao calor do eletrocautério, adere firmemente como um coágulo ao leito sangrante e interrompe a hemorragia menor. Essa hemostasia não é eficaz para vasos maiores, principalmente se forem arteriais. Quanto à alternativa de secção esplênica com grampeador, utilizada no primeiro paciente, já é conhecida na literatura recente $\mathrm{e}^{21,24,27,29,30}$.

$\mathrm{O}$ auto-implante esplênico foi inicialmente indicado para completar esplenectomia total por trauma ${ }^{26}$. Essa operação é fundamentada na esplenose, em que fragmentos esplênicos implantam-se aleatoriamente em qualquer parte do corpo após trauma esplênico. Estudos experimentais indicaram que o melhor local para realizarem-se os implantes é o omento maior ${ }^{4,5,6,7,7,28}$. Essa escolha não se deve unicamente ao rico aporte sangüíneo dessa estrutura, mas também ao fato de sua drenagem venosa seguir para o fígado através do sistema porta, que é também a via natural de drenagem venosa do baço. Constatou-se em experimentos prévios que a boa função do baço depende dessa drenagem para o fígado $0^{5,6,12,16,28}$. 
Um outro aspecto importante com relação à função dos auto-implantes é a quantidade de tecido implantada. Assim como a maioria dos órgãos, o baço precisa de pelo menos $20 \%$ a $25 \%$ de seu tecido para não entrar em insuficiên$\mathrm{cia}^{4,8}$. Dessa maneira, se forem implantados menos de 40 gramas de parênquima esplênico ele irá funcionar, porém de maneira insuficiente. Por esse motivo, foi realizado o implante de 20 fragmentos, pesando um total próximo de 80 gramas.

As operações esplenorredutoras, até por via laparoscópica, são um grande avanço terapêutico, que está cada vez mais bem aceito na literatura para preservar as funções do baço ${ }^{21,24,27,30}$. No entanto, os auto-implantes ainda não foram adotados de maneira mais generalizada, apesar de comprovadas sua eficácia e facilidade técnica ${ }^{4,6,7,8,28}$. Mesmo assim, muitos médicos não acreditam que os fragmentos esplênicos implantados apresentem função adequada. Parte desse preconceito se deve aos resultados ruins publicados antigamente, quando os implantes eram realizados de maneira inapropriada com o aproveitamento de um ou dois segmentos pequenos suturados em locais impróprios, como músculos e tecido subcutâneo.

Existem muitas táticas de implantar o tecido esplênico. Alguns cirurgiões preferem suturar cada fragmento com pontos separados ou colocá-los em bolsas individuais de omento maior. $\mathrm{O}$ tamanho dos segmentos também varia desde pequenas fatias finas até grandes pedaços de baço ${ }^{4}$. Estes autores consideram a sutura contínua de todos os implantes sobre o omento maior, que depois é enrolado sobre os implantes, a forma mais rápida e eficaz de realizar esse procedimento. O fio de Vicryl ${ }^{\circledR}$ utilizado foi por ele ser melhor visto à laparoscopia. Nas operações abertas, há a preferência pelo categute cromado 3-0. Não há necessidade de o fio ser inabsorvível, pois em poucas horas o tecido esplênico adere ao novo leito de inicia o processo de vasculogênese $\mathrm{e}^{18,21}$.

Esta experiência com auto-implante esplênico se deve aos casos em que a proposta inicial era esplenectomia subtotal, mas que por diversos motivos não pôde ser realizada. Todos estes doentes evoluíram muito bem e sem complicação alguma relacionado ao tecido esplênico implantado. Os exames hematológico, imunitário e cintilográfico comprovaram o bom funcionamento dos implantes após três meses da operação ${ }^{18,22,26}$.
Os bons resultados obtidos com os doentes deste estudo confirmam trabalhos prévios clínicos, que revelaram a possibilidade de preservação do pólo superior do baço, quando o seu pedículo precisa ser ligado e seccionado, bem como a realização de auto-implantes, quando não for factível operação esplenorredutora in situ ${ }^{9,10,11,13,14,15,17,18,19,20,22,25}$.

Considera-se fundamental ressaltar a factibilidade da esplenectomia subtotal e dos implantes de tecido esplênico autógeno por via laparoscópica, de maneira simples, sem dificuldade e com os recursos habitualmente utilizados em todas as laparoscopias. Essas operações são seguras e, nos três casos em que aqui foi realizada, não houve adversidades per ou pós-operatórias. Todavia deve-se ter em conta que os baços operados eram de tamanho normal. É muito provável que a esplenomegalia traga dificuldades a esse procedimento e a operação laparoscópica com o auxílio da mão pode ser útil nos baços maiores ou que apresentem particularidades de difícil solução laparoscópica. Por meio de laparotomia, a esplenectomia subtotal pode ser realizada em baços com peso até superior sete quilogramas, sem a necessidade de recursos especiais.

Assim como em outras operações, tanto a esplenectomia subtotal quanto os auto-implantes por via laparoscópica foram acompanhados de evolução menos dolorosa e com recuperação mais rápida dos doentes. Seu retorno às atividades habituais também se faz em período menor do que após laparotomia. Sob aspecto estético, a laparoscopia também é mais satisfatória para os doentes. Dentre as opções terapêuticas esplenorredutoras para doenças hematológicas - esferocitose, eliptocitose, talassemia, hemangiomas, hamartomas e cistos -, a esplenectomia subtotal laparoscópica deve ser considerada.

Não há dúvida de que experiência maior e por tempo mais prolongado é necessária antes de estabelecer-se conduta em relação à esplenectomia subtotal e aos auto implantes esplênicos laparoscópicos.

\section{CONCLUSÃo}

A esplenectomia subtotal e os implantes esplênicos autógenos são factíveis por via laparoscópica de maneira segura para os doentes, e esses procedimentos devem ser considerados no tratamento da dor de origem isquêmica do baço.

Petroianu A, Cabezas-Andrade MA, Berindoague-Neto R. Conservative laparoscopic operations of the spleen for treatment of splenic pain due to ischemia. ABCD Arq Bras Cir Dig 2007;20(1):17-22.

ABSTRACT - Background - Since 1979 this group of authors is doing conservative splenic surgical procedures by mean of subtotal splenectomy and splenic autotransplantation. These procedures were used in over 300 patients to treat different pathological conditions. Aim - To present for the first time in the world subtotal splenectomy and splenic autotransplantation by laparoscopic means, as a new treatment for severe pain due to ischemic spleen. Methods - Three patients presented left abdominal severe pain due to diffuse ischemia of the spleen. This symptom was resistant to all conservative treatment. Laparoscopic subtotal splenectomy, with preservation of the upper splenic pole was indicated in two cases because this was the only part of the spleen without signs of ischemia. In a third patient ischemia was diffuse and total splenectomy with 20 implants of the splenic tissue on the greater was carried out. Results - These procedures were safely conducted with minor bleeding and no technical difficulties or complications. The postoperative follow-up has been uneventful and hematological, immunological, tomographic and scintigraphic exams confirmed the vitality and functionality of the splenic remnants. The pain disappeared since the first postoperative day in the three patients. Conclusion - It is feasible and safe to perform subtotal splenectomy and splenic autotransplants by laparoscopy and these procedures seem to be a good treatment for pain due to ischemic spleen.

HEADINGS - Splenectomy. Partial splenectomy. Subtotal splenectomy. Splenic autotransplant. Laparoscopic splenectomy. Ischemic spleen. Splenic pain. 


\section{REFERÊNCIAS}

1. Carroll BJ, Phillips EH, Semel CJ, Falls M, Morgenstern L. Laparoscopic splenectomy. Surg Endosc 1992; 6: 183-6.

2. Corcione F, Cuccurullo D, Caiazzo P, Settembre A, Bruzzese G, Vittoria I, Cusano T. Laparoscopic partial splenectomy for a splenic pseudocyst. Surg Endosc 2003; 17:1850.

3. Delaitre B, Maignen B. Splenectomie par voie laparoscopique. Presse Med 1991; 20: 2263

4. Iinuma H, Okinaga $\mathrm{K}$, Sato $\mathrm{S}$, et al. Optimal site and amount of splenic tissue for autotransplantation. J Surg Res 1992; 53: 109-16.

5. Leemans R, Manson W, Snijder JAM et al. Immune response capacity after human splenic autotransplantation. Ann Surg 1999; 229: 279-85.

6. Marques RG, Petroianu A, Oliveira MBN, et al. Bacterial clearance after total splenectomy and splenic autotransplantation in rat. Apll Rad Isotopes 2002; 57: 767-71.

7. Marques RG, Petroianu A, Coelho JM, Portela MC. Regeneration of splenic autotransplants. Ann Hematol 2002; 81: 622-6.

8. Nielsen JL, Sakso P, Sorensen FM, et al. Demonstration of splenic functions following splenectomy and autologous spleen implantation. Acta Chir Scand 1984; 150: 469-73.

9. Petroianu A. Esplenectomia subtotal e anastomose esplenorrenal proximal para o tratamento da hipertensão portal. Rev Bras Cir 1983; 73: 101-4.

10. Petroianu A. Treatment of portal hypertension by subtotal splenectomy and central splenorenal shunt. Postgrad Med J 1988; 64: 38-41.

11. Petroianu A. Subtotal splenectomy and portal-variceal disconnection in the treatment of portal hypertension. Can J Surg 1993; 36: 251-4.

12. Petroianu A, Simal CJR, Barbosa AJA. Assessment of phagocytic function in remnants of subtotal splenectomy and in autologous spleen implantation. Med Sci Res 1993; 21: 715-7.

13. Petroianu A. Treatment of cystadenoma of the pancreatic tail by distal pancreatectomy and subtotal splenectomy. Dig Surg 1995; 12: 259-61.

14. Petroianu A. Subtotal splenectomy in Gaucher's disease. Eur J Surg 1996; 162: $511-3$

15. Petroianu A. Subtotal splenectomy for treatment of patients with myelofibrosis and myeloid metaplasia. Int Surg 1996; 81: 177-9.
16. Petroianu A, Silva RG, Simal CJR, Carvalho DG, Silva RAP. Late postoperative follow-up of patients submitted to subtotal splenectomy. Am Surg 1997; 63: 735-40.

17. Petroianu A, Petroianu LPG. A twelve-year-follow-up of subtotal splenectomy and central splenorenal shunt for treatment of schistosomatic portal hypertension. Folha Méd 1998; 116: 107-9.

18. Petroianu A, Vidigal FM, Costa VC, et al. Splenic autotransplantation in Gaucher's disease. Dig Surg 2000; 17: 181-3.

19. Petroianu A. Subtotal splenectomy for treatment of retarded growth and sexual development. Minerva Chir 2003; 58: 413-4.

20. Petroianu A. Subtotal splenectomy for the treatment of chronic lymphocytic leukemia. Ann Hematol 2003; 82: 708-9.

21. Petroianu A, Berindoague RN. Laparoscopic subtotal splenectomy. Minerva Chir 2004; 59: 501-5.

22. Petroianu A, Petroianu LPG. Splenic autotransplantation combined with splenectomy and portal-variceal disconnection in the treatment of portal hypertension. Can J Surg 2005; 48: 382-6.

23. Poulin EC, Thibault C. The anatomical basis for laparoscopic splenectomy. Can J Surg 1993; 36: 484-8.

24. Poulin EC, Thibault C, Côteaux JG, Côté G. Partial laparoscopic splenectomy for trauma. Surg Laparosc Endosc 1995; 5: 306-10.

25. Resende V, Petroianu A. Subtotal splenectomy for treatment of severe splenic injuries. J Trauma 1998; 44: 933-5.

26. Resende V, Petroianu A, Junior WCT. Autotransplantation for treatment of severe splenic lesions. Emerg Radiol 2002; 9: 208-12.

27. Seshadri PA, Poulin EC, Mamazza J, Schlachta CM. Technique for laparoscopic partial splenectomy Surg Laparosc Endosc Percut Tech 2000; 10: 106-9.

28. Thalhamer J, Leitner W, Kurz ME, et al. Immunoarchitecture and specific functions of splenic autotransplants at different implantation sites. Eur Surg Res 1992; 24: 22-36.

29. Uranüs S, Kronberger L, Kine JK. Partial splenic resection using the TA-stapler. Am J Surg 1994; 168: 49-53.

30. Uranüs S, Pfeifer J, Schauer C, Kronberger L, Rabl H, Ranftl G et al. Laparoscopic partial splenic resection. Surg Laparosc Endosc 1995; 5: 133-6.

Conflito de interesse: não há

Fonte financiadora: não há

Recebido para publicação em: 11/07/2006 Aceito para publicação em: 13/11/2006 